\title{
Information Technology Outsourcing: Infiuence of Supplier Firm Size and Reputation on Buyers' A Priori Perceptions of Opportunism and Uncertainty
}

\author{
Imran M. Khan \\ University of Nebraska-Lincoln, USA \\ Email: ikhan3@unl.edu (Corresponding Author)
}

Brian N. Rutherford

Coles College of Business,

Kennesaw State University, USA

\author{
Alvin J. Williams \\ Department of Marketing and Quantitative Methods, Mitchell College of Business, \\ University of South Alabama, USA
}

\begin{abstract}
Growth in outsourcing has led to a renewed focus on vendor and/or business partner evaluation and selection criteria as inept selection can have an adverse impact on core organizational outcomes such as revenues and profitability. Outsourcing activities include use of a third party to perform a variety of business functions such as contract manufacturing, sales, distribution, public relations, and information technology (IT) management. While transaction cost analysis (TCA) researchers have extensively studied outsourcing arrangements, they have not examined how vendor firm characteristics affect buyers' a priori or pre-contract perceptions of opportunism and uncertainty during the vendor evaluation phase. Similarly, while the procurement research stream has identified and explained a range of supplier characteristics and their effect on buyer's vendor selection processes, it lacks integration with TCA. This paper purports to advance both TCA and vendor selection research streams by studying the influence of supplier firm size and reputation on buyers' pre-contract perceptions of opportunism and uncertainty. Higher opportunism and technological uncertainty perceptions in a pre-contract stage can prevent a vendor or channel partner from winning business. Support is found for a relationship between vendor firm reputation and buyers' a priori perceptions of opportunism and uncertainty. Results further show that stronger reputation can mitigate the perception of opportunism, larger firm size, on the contrary, raises the degree of perceived opportunism. Results also support a relationship between opportunism and technological uncertainty.
\end{abstract}

Keywords: transaction cost, opportunism, uncertainty, outsourcing, reputation

\section{INTRODUCTION}

As the global business environment becomes more dominated by services, demand for outsourced business services continues to grow at a rapid rate. Improvements in technology, growth in competition, and the continuing movement toward globalization, that has led to reduced trade barriers among nations, is further spurring utilization of outsourced business services to both domestic and offshore vendors. Outsourcing is defined as the use of external firms to perform a range of business functions that otherwise would be performed in-house (Gilley \& Rasheed, 2000).

From a marketing perspective, outsourced activities range from use of third-parties or channels, such as retailers, to target and serve customers to utilization of independent accounting firms to process payroll functions. Within the wireless service industry, for instance, firms such as Verizon and AT\&T routinely use outsourced channels known as authorized resellers to market their services. Similarly, medical device vendors such as General Electric, Siemens, and others often use third party vendors to manufacture their devices under a licensing arrangement. In addition, the use of independent agents is rather prevalent for selling and servicing both medical and industrial equipment.

Outsourcing is also extensively employed in the information technology (IT) industry whereby organizations often outsource network security, hardware, and application management to IT consultants and systems integrators. For instance, several organizations across manufacturing, healthcare, retailing, and financial services are employing outsourced cloud computing solutions from firms such as Amazon Web Services (AWS), IBM, and Microsoft Corporation. Similarly, use of outsourced customer relationship management $(\mathrm{CRM})$ as well as enterprise resource planning (ERP) tools from vendors such as Oracle is rather prevalent in the market. Moreover, with the growth in analytics and big data, organizations are employing cloudbased outsourced data intelligence solutions from vendors such as SAS. Within the context of business services, outsourcing often involves offshoring. Pore (2018, p. 1) states that "because of globalization and advancements in information and communication technology offshoring of services has emerged as an important strategy for businesses to either reduce cost and/or access resources."

The decision to outsource a business function is rather 
complex in that it requires identification of processes and/or functions that are targeted for outsourcing as well as selection of a vendor and/or solution provider. In that regard, organizations choose from small, medium, and large vendors that vary in their capabilities. Ineffective selection of an outsourcing provider can expose the buying firm to a variety of risks such as loss of control, dependence, lower margins or profits, and degradation of product/service quality (Bahli \& Rivard, 2003; Bellin, 2015). These risks, when materialized, can defeat the very objectives behind outsourcing as the buyer may find itself making costly postcontractual changes or investing in monitoring systems (Walker \& Weber, 1984, Williamson, 1975). In some cases, it may also lead to terminating an existing relationship and having to select another vendor.

The academic community has examined outsourcing issues from various angles. Within this literature, transaction cost analysis (TCA) is often employed as the theoretical foundation (e.g., Bahli \& Rivard 2003; Paswan, 2009; Wang 2002) for studying inter-firm relationships. However, extant TCA literature primarily focuses on evaluating the impact of transaction attributes and behavioral factors on an organization's make-or-buy decision. TCA framework has not been applied in the context of vendor and/or channel evaluation and selection processes.

The purpose of this paper is to study the influence of supplier or vendor firm characteristics on organizational buyers' a priori or pre-contract perceptions of overall transaction costs (vendor opportunism and uncertainty) within a B2B outsourcing services context. Firm characteristics of size and reputation are at the core of most supplier/vendor/channel evaluation as well as buyer-seller relational exchange research (e.g., Doney \& Cannon, 1997; Ganesan, 1994). However, TCA researchers have not studied vendor opportunism and uncertainty within the supplier evaluation and selection context. Supplier firm size and reputation can signal to the buyer the extent to which an organization is capable and likely to deliver on the terms of the outsourcing arrangement - whether it involves reselling merchandise on behalf of a manufacturer or providing IT services to an enterprise buyer such as a bank. Similarly, vendor evaluation and selection research has excluded opportunism and uncertainty associated with the outsourcing provider in its analysis (e.g., Hsu, Kannan, Leong, \& Tan, 2006; Petroni \& Braglia, 2000).

Opportunism, defined as self-interest seeking with guile (Williamson, 1975), and uncertainty, defined as inability to anticipate environmental changes and evaluate supplier performance (Rindfleisch \& Heide, 1997), are central constructs within the TCA research stream. Understanding of linkages between firm attributes and buyers' a priori (pre-contract) perceptions of opportunism and uncertainty associated with the outsourced vendor or supplier is likely to reduce the likelihood of selecting a dysfunctional business partner. Both opportunism and uncertainty are shown to influence a range of outcomes such as service quality and costs in an outsourcing arrangement (Wathne \& Heide, 2000). At the same time, TCA scholars (Brown, Krishen, \& Dev, 2014; Rindfleisch \& Heide, 1997) examined various antecedents of opportunism in inter-firm relationships but did not incorporate supplier firm characteristics as indicators of pre-contract opportunism.

Moreover, both transaction cost and outsourcing research paths have focused on ex post (post-contract) opportunism and uncertainty and how they influence the make or buy decision as well as relationship governance mechanisms (Lonsdale, 2001; Mysen, Svensson, \& Payan, 2010; Stump \& Heide; 1996; Wang, 2002). Opportunism, however, can emerge in both ex ante/a priori (pre-contract) and ex post (post-contract) stages in an inter-firm relationship.

Tumbat and Grayson (2016) contend that one of the key questions faced by a company revolves around implementing mechanisms that can help reduce the incidence of suppliers delivering low quality products. While many of these can be post hoc or ex post controls, this paper proposes using supplier firm characteristics as a proxy for anticipating opportunism during the pre-contract stage. Measurement of a priori opportunism and uncertainty perceptions can help institutional and other industrial buyers reduce the risk of adverse selection i.e., the likelihood of engaging in a relationship with a vendor or a channel partner that lacks required capability or commitment (Eisenhardt, 1989). Therefore, by linking vendor firm characteristics to buyers' a priori perceptions of opportunism and uncertainty, this research extends the traditional transaction cost perspective beyond governance mechanisms to one that involves vendor/supplier evaluation and selection.

A second contribution of this research is that it expands existing supplier selection research and purchasing literature. Both opportunism and uncertainty, while impacting important outcomes in buyer-seller exchanges (Wathne \& Heide, 2000), have not been combined with vendor/channel evaluation and selection variables such as firm size and reputation in a priori context. Digalwar, Borade, and Metri (2014) allude to the multi-dimensionality of vendor selection decisions and processes in that such decisions encompass both tangible and intangible factors. This paper identifies vendor reputation and size as variables that align with the tangible and intangible dimensions of supplier selection decision.

A third contribution of this research focuses on helping business-to-business service providers identify and understand how their firm characteristics affect buyers' precontract perceptions of potential opportunism and uncertainty as higher degree of opportunism and uncertainty perceptions can influence an organization's decision to outsource (Ang \& Straub, 1998; Earl, 1996), thereby reducing revenue growth opportunities for outsourced service providers. Such understanding can also help outsourcing providers develop and implement marketing mix strategies that aim at improving their overall brand perception and product/service positioning. Similarly, from a buyer or manufacturer's viewpoint, effective comprehension of the relationship between firm characteristics and transaction cost constructs of opportunism and uncertainty can provide them with a holistic perspective on the evaluation and selection process for outsourced service providers. This paper utilizes an outsourced IT services context to test the relationship between vendor firm attributes and the resulting impact on buyers' perceptions of opportunism and uncertainty.

\section{THEORETICAL BACKGROUND}

The expansion of outsourced services has attracted the 
attention of scholars from various schools of thought, including TCA, agency theory, service quality, and buyerseller relational exchange (e.g., Cannon \& Perreault, 1999; Mahaney \& Lederer, 2011; Niranjan \& Metri, 2008; Tiwana \& Bush, 2007; Williamson, 2008). In fact, TCA, the conceptual focus of this paper, constitutes the predominant foundation for outsourcing research as can be evidenced from the large number of outsourcing studies employing various TCA constructs (Bhali \& Rivard 2003; Hawkins, Knipper, \& Strutton, 2009; Lonsdale, 2001; Stump \& Heide, 1996; Wang 2002).

TCA was initially developed by Coase (1937) and expanded upon by Williamson (1975). Transaction cost is at the heart of outsourcing as well as inter-firm relational exchange research (e.g., Heidi, 1994; Mysen et al., 2010; Wang, 2002). The fundamental premise of TCA is whether a particular transaction can be performed more efficiently within an organization or by outside firms (Geyskens et al., 2006). TCA research shows that while in-house product development allows for better governance mechanisms and control over operations (Rindfleisch \& Heide, 1997), outsourcing provides firms with significant cost advantages and faster time to market (MacFarlan \& Nolan, 1995). However, outsourcing can also expose the buyer to a variety of risks including unreliable service, lock-in agreements that eliminate organizational flexibility to switch vendors and may lead to potential litigation costs (Bhali \& Rivard, 2003).

Current TCA research, however, has focused on the post-contract behavioral (opportunism) as well as transaction-related attributes (uncertainty). There is a general lack of emphasis on analyzing how vendor firm attributes influence buyers' perceptions of opportunism and uncertainty in an a priori or pre-contract stage since buyers' negative perceptions on those two variables can constrain the ability of an outsourcing vendor to win business.

Within the relational exchange and vendor selection literature streams, various scholars have studied the influence of variables such as vendor size, mutual trust, commitment, long-term orientation, reputation, cost, quality, information exchange, and relationship-specific investments on buyer-seller relationship and related outcomes (Kwon \& Suh. 2004; Macneil, 1980; Morgan \& Hunt 1994; Ono \& Kubo, 2009; Pearson \& Ellram, 1995; Petroni \& Braglia, 2000). Such research, however, excluded the TCA constructs of opportunism and uncertainty. This paper integrates two distinct, yet related, theoretical streams including transaction cost and vendor evaluation in studying how vendor firm attributes affect buyers' pre-contract perceptions of opportunism and uncertainty as such perceptions can have a material impact on key outcomes such as the desire to outsource.

\subsection{Construct Overview}

This section provides an overview of the various constructs depicted in the conceptual model (Figure 1). Moreover, the section also leverages literature to illustrate the theoretical relationship between vendor/supplier firm attributes and transaction cost variables. More specifically, the hypotheses offers linkages between vendor/supplier firm size and reputation and buyers' perception of opportunism and uncertainty during the pre-contract stage.

Vendor firm size is described in terms of the number of employees or the annual revenue for a particular firm. When purchasing outsourced services, the buying firms have to choose from among small, medium, and large vendors that may offer comparable services at comparable prices. However, these vendors often vary in other facets of their operations such as geographic reach, customer support, and brand awareness. The size of a seller or a buyer is also equated with the degree of power one exchange member will have over another (Anderson \& Narus, 1990). Dependence of one party in an exchange on the other is cited as a variable that exposes the dependent party to the risk of opportunism (e.g., Geyskens et al., 2006; Nooteboom, 1993). A small supplier, for instance, is likely more dependent on a larger buyer (Larson, Carr, \& Dhariwal, 2005), specifically if the buyer accounts for a majority of the supplier's business (Krause, Ragatz, \& Hughley, 1999). Under that scenario, a smaller supplier may find it necessary to comply with the buyer's demands such as changes in quantity ordered and/or product specifications.

For instance, as Walmart implemented the use of radio frequency identification systems to improve inventory control and management, smaller suppliers had two options, i.e., abandon the relationship with Walmart or absorb the high cost of deploying radio frequency identification systems. Similarly, Morgan (2000) found that small suppliers are reluctant to implement electronic data interchanges as they view these as more advantageous for their larger buyers.

Conversely, a small buyer may have more dependence on a larger supplier and hence may be at a disadvantage when the supplier increases its prices. For instance, an increase in micro-processor prices by Intel, a major component provider to the computing industry, is likely to have a greater negative impact on smaller computer manufacturers than larger ones. Unlike smaller buyers that often buy small quantities, larger firms may be able to offset the effects of price increases through volume discounts.

Firm size is also equated with a supplier organization's capabilities. As indicated by Nooteboom (1993), small firms lack economies of scale and therefore are unable to allocate resources to expand their expertise. With regard to outsourcing, a small vendor may find it difficult to offer around the clock customer support due to high costs of developing such capability as well as the reduced number of customers over which to spread costs. Small suppliers may also find it difficult to develop frequent product updates or improvements due to their limited resources.

Vendor reputation is described as a multi-faceted construct and involves aspects such as reliability, honesty, and trustworthiness (Ring \& Van de Ven, 1992; Weigelt \& Camerer, 1988). Doney and Cannon (1997) further classify reputation as the extent to which industry participants believe a supplier is not just honest, but also concerned about its customers. Vendor reputation is a key variable in inter-firm relational exchanges as it is shown to influence important outcomes including opportunism (Wang, 2002) and trust (Ganesan, 1994; Kwon, 2004). From a relational exchange perspective, a supplier's desire to protect its reputation serves as a deterrent against opportunism (Houston \& Johnson, 2000). Manello and Calabrese (2019) suggest that firm reputational factors are more pertinent in supplier selection than just the performance-related factors. This is due to the fact that aggregate supplier reputation is likely to 
be a much more holistic measure than individual performance measures such as timely deliveries.

Given the transaction cost assumption of bounded rationality whereby a buyer is unable to anticipate and incorporate all contingencies in a formal contract, vendor reputation may be able to serve as a cue or signal of vendor trustworthiness (Sarkis \& Talluri, 2002). Specifically in the pre-contract or ex ante stage and in situations where a past relationship with the vendor is non-existent, the importance of positive vendor reputation cannot be undermined. Since positive reputation increases buyers' trust in a vendor (Doney \& Cannon, 1997), the need for costly postcontractual (ex post) monitoring and management of a vendor is, therefore, minimized. While both transaction cost and outsourcing researchers have evaluated the impact of reputation on variables including outsourcing project success (Wang, 2002), the effects of vendor reputation on reducing buyers' pre-contract perceptions of uncertainty in an exchange have not been evaluated.

Opportunism is defined as "self-interest seeking with guile (Williamson, 1975, p. 6). "Opportunism includes a variety of behaviors including lying, cheating, misleading, shirking, and deceit" (Williamson, 1985, p. 47). Wathne and Hiede (2000, p. 38) state "what sets opportunism apart from the standard economic assumption of self-interest seeking behavior is the notion of guile." Opportunism is a key behavioral construct in TCA research and one that has been studied in the inter-firm relationship (e.g., Hawkins et al., 2009; Stump \& Heide, 1996) as well as outsourcing (Wang, 2002) literature. Aubert, Patry, and Rivard (1998) suggest the likelihood of a buyer and or its supplier to default on the terms of the agreement is present in each outsourcing arrangement. Given the assertion by Aubert et al. (1998), it is therefore necessary for both the buyer and the supplier to identify and understand the impact of various opportunism antecedents.

Opportunism can be manifested in the ex ante (precontract) as well as ex post (post-contract) stages of a transaction. For instance, in the pre-contract stage, a vendor may misrepresent information about its capabilities and resources (Williamson, 1985) while in the ex post stage a vendor may change product quality in order to reap better margins (Wathne \& Heide, 2000). In the ex ante stage, vendor opportunism and bounded rationality on the part of the buyer may lead to adverse selection, whereby the principal or the buyer cannot observe or verify the characteristics of the agent (Aubert et al., 1998), thereby tying a buyer into a non-conducive relationship. Jap et al. (2013) suggest that while opportunistic behavior is more likely to occur under high-stakes conditions, rapport between the buyers and sellers serves as a moderator of such relationship. Lee and $\operatorname{Kim}(2018$, p. 40) in their study on market power, environmental uncertainty, and opportunistic behavior argue that "it is very important for marketing managers to control opportunistic behavior and to reduce transaction costs." Such control mechanisms, however, are post-contractual measures which involve implementation and monitoring costs and are less likely to assist buyers in their ex ante vendor evaluation and selection.

Williamson (1996) contends that although strong governance mechanisms can limit the extent of ex post opportunism, such tools are unlikely to completely rid an inter-firm arrangement of the threat of post-contractual opportunism. In order to constrain the incidence of ex post opportunism, it is important for a buying firm to study ex ante variables such as vendor firm characteristics which may affect the degree of ex post opportunism. In that regard, this paper focuses on buyers' ex ante perceptions of opportunism related to a particular vendor or supplier.

Uncertainty is identified as a transaction (as opposed to behavioral) dimension within the TCA framework and involves the inability of the parties to anticipate all pertinent contingencies related to an exchange. Moreover, uncertainty also refers to the incapability to evaluate performance in an inter-firm relationship (Geyskens et al., 2006). Uncertainty, according to Rindfleisch and Heide (1997), creates an adaptation problem in that contracts would need to be rewritten or renegotiated if and when variations occur in the circumstances surrounding a buyer-seller exchange. For instance, an electronic medical record software provider may develop product updates that can render the software incompatible with other billing and operational systems deployed by a hospital (the buyer). Under such a scenario, the hospital may have limited choice but to either replace the application provider or pay for costly integration services that would make the new application compatible with legacy systems.

The definition of technological uncertainty, which is a subset of environmental uncertainty, varies among scholars. For instance, Stump and Heide (1996) and Walker and Weber (1984) view it as difficulties in accurately forecasting the technical requirements in an exchange. This is generally the case for many outsourced IT services whereby technical requirements often need to be revised several times over the course of the project. In addition to the difficulties associated with defining technological specifications within an outsourced project, Stump and Heidi (1996) as well as McNally and Griffin (2004) further equate technological uncertainty with the risk of obsolescence.

\section{HYPOTHESES DEVELOPMENT}

This section offers a review of the linkages between vendor firm attributes and buyers' perceptions of opportunism and technological uncertainty associated with a vendor. From a buyers' perspective such linkages can help them not just with vendor selection but also affect their relationship governance strategies.

\subsection{Linking Firm Size to Opportunism}

Doney and Cannon (1997) argue that buyers can use a transference process, through which they may rely on the experiences of others, to determine the trustworthiness of a supplier based on its firm size. In that regard, vendor firm size can offer a buyer several insights into a supplier. Small firms, for instance, typically have limited resources including research budgets and managerial capabilities. This renders them at a disadvantage in terms of investments in research and development as well as other operational functions such as customer support. Given that smaller firms are less likely to rely on economies of scale, it can have an impact on a supplier's internal costs as well as its pricing strategies. For instance, smaller advertising agencies are likely to pay higher rates when purchasing media compared to large firms that are not only able to command lower prices but are also able to spread media costs over many clients 
thereby keeping their rates low for individual clients. Same is the case with smaller software vendors that typically have a single offering.

Dean, Brown, and Bamford (1998) state that small firms face limitations in raising financial resources compared to large firms. In the context of outsourcing, lack of financial resources can impact the ability of a vendor to expand and/or upgrade its facilities, such as customer support, in order to meet the growing needs of its customers. Furthermore, Larson et al. (2005) state that small firms, due to their limited resources, are more likely to focus on short-term gains and benefits. Such short-term focus is often aimed at managing cash flows necessitated by the lack of diverse revenue streams. However, short-term orientation or the focus on short-term gains by an economic actor is also cited as a condition that serves as an antecedent or precursor to opportunism while long-term orientation suppresses opportunism (Doney \& Cannon, 1997; Hill, 1990). Within the IT services outsourcing segment, large vendors such as IBM typically face stronger competitive intensity due to the presence of other heavy-weight rivals. Stronger competitive intensity or competitive severity is shown to have a negative relationship with opportunistic behavior (Paswan, 2009). This is likely due to the need for differentiation as well as maintaining or growing market share which prompts vendors to be more customer-centric.

Doney and Cannon (1997, p. 38) state that "supplier size provides a signal to the buying firm that the selling firm can be trusted," given that larger vendors or suppliers often have larger market shares thereby reflecting the notion that many buyers trust the seller. In situations where a buyer may not have a past relationship with a particular vendor, supplier firm size serves as a basis for "transferring trust to unknown or untried suppliers, relying on the experience of others," (Doney \& Cannon, 1997, p. 47). With regard to smaller firms, their lower market share or fewer customers as well as their private ownership structure is also likely to render it difficult for buyers to cost-effectively verify the vendors' capabilities a priori or in the vendor evaluation stage.

Within an outsourcing context, therefore, a smaller supplier due to its focus on short-term survival (Larson et al., 2005) is likely to inflate its capabilities when bidding on a contract. Moreover, a smaller vendor is also likely to engage in post contractual shirking (such as service quality debasement) due to its limited resources thereby leading to the following hypothesis:

H1: In a service outsourcing situation, as vendor firm size increases, buyers' a priori perceptions of vendor opportunism decrease.

\subsection{Linking Firm Size to Technological Uncertainty}

From a technological uncertainty perspective, small vendors, due to their limited financial resources as well as lack of expertise (Dean et al., 1998) are likely to face a higher degree of technological uncertainty. Such uncertainty may revolve around their inability to make frequent product improvements. In a study of small minority suppliers, Krause et al. (1999) found that smaller suppliers indicated their firms were frequently undercapitalized. Lack of access to capital can impair a firm's ability to undertake necessary investments in improving its products/services as well as expanding its facilities. Therefore, a vendor that lacks in economies of scale, scope, experience, and learning is less likely to make cost-effective adaptations to the changing needs of the relationship.

Larson et al. (2005) contend that despite the declining costs of technology, investments in new systems remain cost-prohibitive for small firms. Within the healthcare services industry, for instance, hospital information systems remain in a state of flux as hospitals migrate to electronic medical records and other applications in order to comply with the changing regulatory environment. For a smaller provider of electronic medical record systems, they may have to make several updates to their product in order to keep it compatible with other software and applications implemented by a hospital. Lack of economies of scale plus capital constraints on the part of smaller vendors is likely to render it difficult for them to develop continuous updates to their systems thereby exposing them to technology obsolescence.

In addition to capital constraints, Larson et al. (2005) also cite that smaller firms generally lack internal expertise to keep pace with the technological changes. Similarly, Chen, Paulraj, and Lado (2004) found that in addition to high cost of technology, lack of technological know-how served as the main barrier to e-commerce adoption among small and medium-sized enterprises. Thus:

H2: In a service outsourcing situation, as vendor firm size increases, buyers' a priori perceptions of technological uncertainty associated with the vendor decrease.

\subsection{Linking Reputation to Opportunism}

With regard to linkages between reputation and opportunism, Hennart (1993) argues that reputation constrains opportunistic behavior on the part of the supplier as such behavior would lead a supplier to lose credibility and hence its ability to win future business in the marketplace. The importance of vendor reputation cannot be underemphasized within the context of B2B services, many of which suffer from performance evaluation (Parasuraman et al., 1985) as well as monitoring difficulties (Hawkins et al., 2009). Also, given that most inter-firm contracts are deemed incomplete (Williamson, 1985), positive reputation is likely to provide the buyer with ex ante or pre-contract assurance that a vendor will be less inclined to act opportunistically ex post/post-contract thereby leading to the following hypothesis:

H3: In a service outsourcing situation, stronger vendor reputation negatively influences buyers' a priori perceptions of vendor opportunism.

\subsection{Linking Reputation to Technological Uncertainty}

With regard to linkages between vendor firm reputation and technological uncertainty, positive reputation conveys a sense of credibility and fairness (e.g., Anderson \& Weitz, 1992; Ganesan, 1994) to the buyers. Given that reputation is generally earned over a period of time and requires significant investments in a range of operational areas, it is also likely to provide buyers with insights into the ability of a vendor to sustain investments in product/service development and improvement. For instance, within the outsourced IT services market, vendors such as IBM, Oracle, 
SAP, and Microsoft have, over the past several decades, built a reputation for offering innovative solutions to their customers. Their positive reputations for superior technological know-how in the marketplace can be evidenced from their large market shares in a multitude of B2B IT services markets. As suggested by Hill (1990), suppliers that are perceived as less trustworthy (i.e., those with less favorable reputations) are unable to garner larger sales or market share, hence establishing a linkage between market share and reputation.

When seeking a new outsourced IT solution such as data analytics software, many buyers are choosing to outsource these solutions from vendors that have a strong reputation in the marketplace as compared to smaller vendors. For instance, a hospital network is much likely to source purchase, implementation, and management of healthcare software from a larger provider like Cerner that has the necessary scale and scope to support large, geographically dispersed branches. Given the extensive scale and scope of their operations, IT solutions from vendors such as IBM are also less likely to face the risk of technological obsolescence than smaller vendors with a less favorable reputation (Doney \& Cannon, 1997). Hoetker (2005, p. 78) in his research on supplier selection for technically innovative components argues that "potential suppliers differ in their technical capabilities and, thus, in their ability to produce a component according to the desired specifications and schedule."

A supplier's reputation can, therefore, signal to the potential buyer whether a vendor can develop a technologically sophisticated product or service as well as its ability to sustain such a solution. Moreover, in complex purchase situations that involve a higher degree of product/service complexity, vendors with a strong reputation for technical know-how are able to help buyers develop such specifications. Thus:

H4: In a service outsourcing situation, as vendor firm reputation increases, buyers' a priori perceptions of technological uncertainty decrease.

\subsection{Linking Opportunism to Uncertainty}

The linkages between environmental uncertainty (including technological uncertainty) and opportunism are well established across extant TCA literature (e.g., McNally \& Griffin, 2004; Mysen et al., 2010). Rindfleisch and Heide (1997), for instance, contend that environmental uncertainty creates adaptation problems in that it may require the parties in an exchange to modify existing contracts in order to fit the changing circumstances (Williamson, 1985). Contractual renegotiation is likely a costly undertaking and one that can be used to gain concessions by an exchange partner
(Hawkins et al., 2009). Crosno and Dahlstrom (2008) argue that environmental uncertainty along with inability to predict an exchange partner's behavior lead to a higher likelihood of opportunism.

Given the high rate of technical change in IT outsourcing arrangements (e.g., Bahli \& Rivard, 2003; Wang, 2002), the advent of new technologies can render existing solutions either obsolete or incompatible thereby forcing exchange partners to renegotiate existing agreements and/or purchase specifications. Within the network access services market, for instance, there is a constant flux of new fiber-based transport technologies that are capable of delivering multiple services (voice, data, and video) over a single platform thereby rendering existing copper-based solutions rather obsolete. From a buyer's perspective, as availability of fiber-based technologies increases, they may find themselves either having to seek new providers or renegotiate contracts with existing suppliers for migration of their voice, data, and video traffic over new network facilities. In either of these situations, buyers are likely to face the risk of vendor opportunism in that the existing provider may not wish to terminate the relationship without charging significant termination fees or charging higher than market prices. Thus:

H5: In a service outsourcing situation, there is a positive relationship between buyers' a priori perceptions of technological uncertainty and opportunism associated with a vendor.

\subsection{Control Variables}

A few key control variables are considered in this study. Specifically, buyer firm size (e.g., Heide, 1994; Larson et al., 2005), idiosyncratic investments (Geyskens et al., 2006), and information exchange/sharing (Cannon and Perreault, 1999) have been shown to influence perceptions of opportunism and uncertainty in an inter-firm relationship and will therefore be examined as controls. Idiosyncratic investments, also termed as asset specificity in TCA literature (e.g., Geyskens et al., 2006, Williamson, 1985), are assets that are employed for a particular transaction and have little if any residual value outside that exchange. Information sharing/exchange is defined by Cannon and Perreault (1999, p. 441) as "expectations of open sharing of information" on the part of both the buyer and the seller. Furthermore, Basnet and Seuring (2016) state that sharing of vital information such as demand data can render many synergies in a supply chain such as inventory management and logistics. Interfirm information sharing provides buyers with greater visibility into supply chain while also enabling sellers to build trust in an exchange. Figure 1 provides an overview of the research model and the hypotheses. 


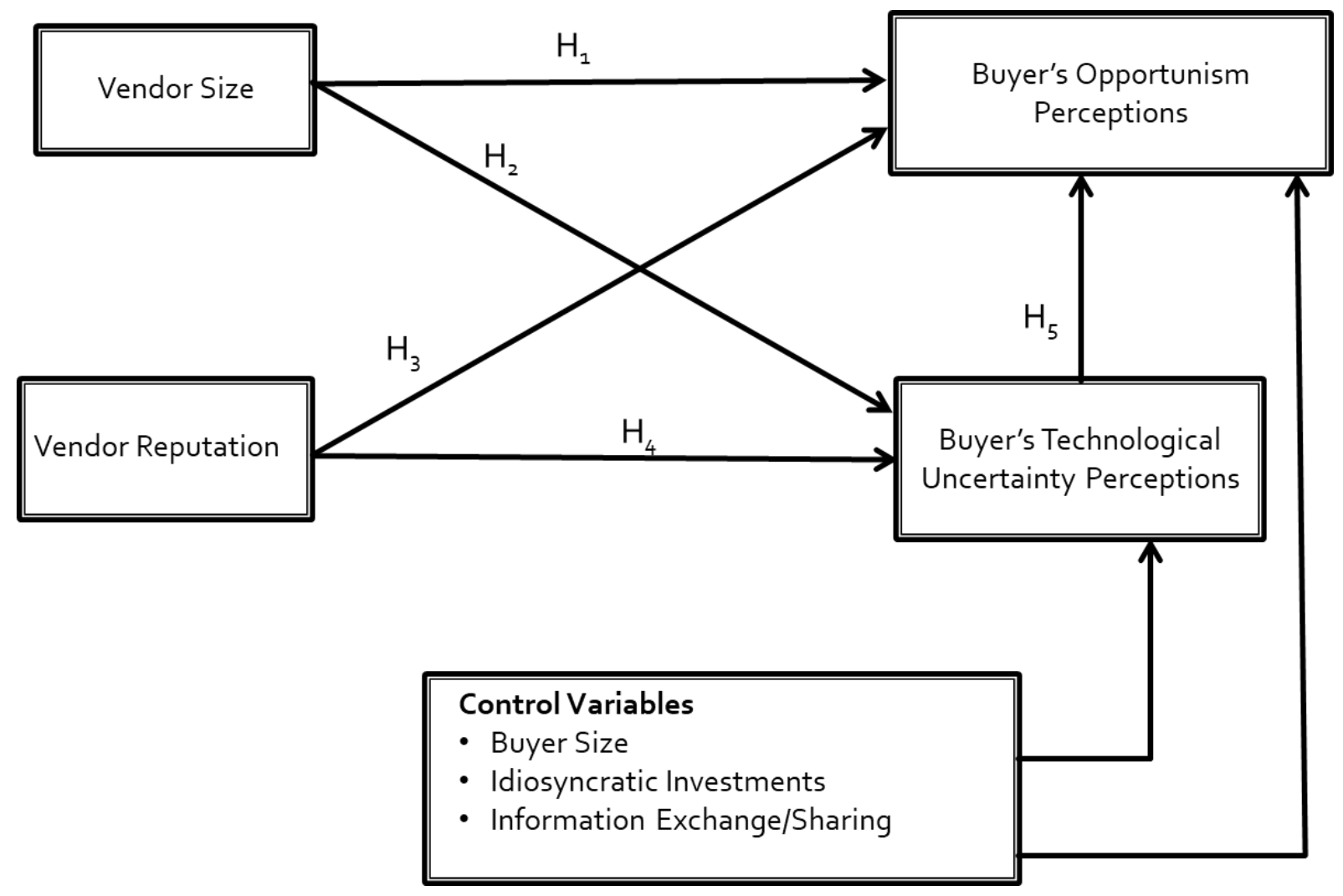

Figure 1 Research model

\section{METHODOLOGY}

An online panel of US-based organizational buyers responsible for IT procurement for their respective organizations was used. The use of an online panel is consistent with the sampling options suggested by Hair, Black, Babin, and Anderson (2010) for cross-sectional studies. An initial pool of 1,478 US-based respondents was contacted via email.

\subsection{Sample Selection and Data Collection}

To complete the survey, respondents had to first complete a screening process. Respondents were asked to identify whether they are involved with their organization's IT outsourcing purchase process, whether they had been involved in an IT outsourcing purchase decision within the past twelve months, and their level of involvement/role in the IT procurement process. Respondents had to have purchase decision-making responsibility for their organizations and also had to be involved in an IT outsourcing decision in the past year to qualify for the survey.

Respondents that met the required criteria were then asked to identify the type of IT solution their organization outsourced, number of vendors evaluated, and names of vendors that were selected as well as of those that were not selected. Respondents were asked to select the vendor they were most familiar with, from among the list of vendors they had evaluated but not selected, and answer a series of questions pertaining to that vendor. Of the 1,478 respondents that were contacted, 502 did not satisfy the screening requirements and were removed. Further, 176 failed to complete the survey and were removed. After assessing for completed surveys, time taken to complete the survey, and other errors, a total of 301 completed surveys were obtained. Thus, the survey yielded a 20.4 percent response rate.

In addition, given the focus of the paper on enterpriselevel IT outsourcing, respondents whose procurement responsibility was below $\$ 1,000 /$ year, whose organizations had fewer than five employees, whose company annual revenues were below $\$ 10,000$, whose overall company IT budget was less than $\$ 1,000$, and who had below one percent of their total IT budget dedicated to outsourcing were also eliminated. Organizations with such traits are more likely to be very small and often home-based business as opposed to a traditional enterprise customer. In total, 203 valid completes were used in the analysis for an effective usable response rate of 13.7 percent. Table 1 provides a summary of respondents' characteristics.

Of the 203 respondents, 72.4 percent had the final purchase authority for their organization's IT purchases including outsourced services. The remaining 27.6 percent either recommended or influenced their organization's IT purchase decisions. Regarding industry affiliation, 24.6 percent of respondents were involved in manufacturing, 7.9 percent in construction and professional services respectively, 6.9 percent in retail trade, 4.4 percent each in telecommunications and educational services, and the remaining 43.9 percent represented a range of other industries. No other individual industry accounted for over 4 percent of total respondents.

\subsection{Measures}

Survey items were adapted from established scales to fit the ex ante or pre-contract context. The vendor reputation scale included eleven items, four from Ganesan (1994) to measure the perceived fairness and honesty aspects of reputation and seven items adapted from the Reputation Quotient (RQ) scale developed by Fombrun, Gardberg, and 
Sever (2000). Vendor size was measured using five-sevenpoint Likert-type items from strongly disagree to strongly agree and were developed by Doney and Cannon (1997). Vendor opportunism was measured using six items adapted from Rokkan, Heide, and Wathne (2003). Vendor technological uncertainty was measured using four items adapted from Stump and Heide (1996).
Buyer size was measured by asking respondents to estimate the number of employees in their organization. Idiosyncratic investments were measured with five-sevenpoint Likert-type scale items used by Anderson and Weitz (1992). Information sharing was measured by a five-item scale that included two items from Doney and Cannon (1997) and three items from Pesamaa and Hair (2007).

Table 1 Survey respondent profile

\begin{tabular}{lc}
\hline Male & $66 \%$ \\
\hline Female & $34 \%$ \\
\hline Number of Years Employed with their Current Organization (median) & 7 \\
\hline Number of Years in IT Procurement (median) & 10 \\
\hline Respondents' Annual IT Procurement Responsibility (median) & $\$ 400,000$ \\
\hline Number of Employees in the Firm (median) & 530 \\
\hline Annual Revenues of the Firm (median) & $\$ 34$ million \\
\hline Annual IT Budget of the Firm (median) & $\$ 750,000$ \\
\hline Percent of Total IT Budget Dedicated to Outsourcing (median) & $25 \%$ \\
\hline
\end{tabular}

\subsection{Research Technique/Data Analysis}

To conduct the data analysis, both SPSS and AMOS were used. First, the measurement model which included seven constructs and 36 items was tested. Then, common method variance, reliability, and both convergent and discriminant validity were examined. Following the initial data assessment, hypothesized linkages were tested using a structural model.

Survey respondent data was tested for common method variance issues (Podsakoff, MacKenzie, Lee, \& Podsakoff, 2003). From a procedural perspective, this paper also utilized scales with varying anchors as well as marker variables (that were used at the mid-point in the survey), in order to reduce the incidence of common method variance. In addition, a one-factor test was also performed on the summated scales for each construct (including control variables) which revealed multiple factors. Common method bias was deemed not an issue within the data.

\section{RESULT}

An initial confirmatory factor analysis (CFA) was performed using guidelines provided by Hair et al. (2010, p. 659) and Hu and Bentler (1999). Specifically, model fit was evaluated using Chi-Square, degrees of freedom, RMSEA (values between .03 and .08), and CFI (values above 0.90). The initial CFA results offered adequate fit (Chi-Square = 1208.99; $\mathrm{DF}=574 ; \mathrm{CMIN} / \mathrm{DF}=2.106 ; \mathrm{CFI}=0.908$; RMSEA = .074). Subsequently, a review of modification indices was done which identified further opportunities to improve the model fit by eliminating items that either had higher unstandardized regression weights (values greater than 10) and also by reviewing standardized residual covariances for values greater than |4|. The final model contained 28 items and good model fit was achieved (ChiSquare $=583.671 ; \mathrm{DF}=330 ; \mathrm{CMIN} / \mathrm{DF}=1.769 ; \mathrm{CFI}=0.95$; RMSEA $=0.062$ ).

Scale reliability was acceptable for all constructs and means and standard deviations provide evidence of acceptable variance captured within the constructs. Next, each construct was examined for convergent and discriminant validity. With regard to convergent validity, all constructs had an average variance extracted (AVE) score above 0.50, all Eigenvalues higher than 1, and all reliability scores above the 0.70 threshold provided by Bagozzi, Yi, and Phillips (1991). With regard to discriminant validity, the AVE scores for each construct must be higher than the squared inter-construct correlations to establish discriminant validity (Fornell \& Larcker, 1981). All constructs exhibit discriminant validity based on this. Table 2 provides a summary of these tests.

The structural model results were acceptable (ChiSquare $=695.587 ; \mathrm{DF}=337 ; \mathrm{CMIN} / \mathrm{DF}=2.064 ; \mathrm{CFI}=$ 0.929; RMSEA = 0.073). Control variables were examined for significant linkages. Only information sharing by vendor was found to have a significant impact on buyers' perceptions of opportunism (p. <.01) and technological uncertainty (p. <.01).

Table 2 Scale reliability \& validity results

\begin{tabular}{lcccc}
\hline Construct & Reliability (a) & Mean & Std. Deviation & $\begin{array}{c}\text { Average Variance } \\
\text { Extracted (AVE) }\end{array}$ \\
\hline Vendor Size (4 items) & 0.895 & 5.088 & 1.342 & 0.687 \\
\hline Vendor Reputation (7 items) & 0.934 & 5.416 & 0.995 & 0.673 \\
\hline Perceived Opportunism (6 items) & 0.971 & 3.617 & 1.974 & 0.849 \\
\hline Perceived Technological Uncertainty (4 items) & 0.910 & 3.858 & 1.386 & 0.720 \\
\hline $\begin{array}{l}\text { Idiosyncratic Investments by Vendor - control (3 } \\
\text { items) }\end{array}$ & 0.895 & 4.827 & 1.356 & 0.747 \\
\hline Information Sharing by Vendor - control (3 items) & 0.915 & 4.277 & 1.724 & 0.788 \\
\hline
\end{tabular}

Note: Buyer size, the third control variable, is excluded from the table given that it was measured using a single item variable (number of employees). 
Table 3 Summary of hypotheses results

\begin{tabular}{lcc} 
Hypotheses & $\begin{array}{c}\text { Unstandardized } \\
\text { Regression Coefficient }\end{array}$ & $\begin{array}{c}\text { Supported /Not } \\
\text { Supported }\end{array}$ \\
\hline $\begin{array}{l}\text { H1: In a service outsourcing situation, as vendor firm size increases, buyers' } \\
\text { a priori perceptions of vendor opportunism decrease. }\end{array}$ & 0.446 & Not Supported \\
\hline $\begin{array}{l}\text { H2: In a service outsourcing situation, as vendor firm size increases, buyers' } \\
\text { a priori perceptions of technological uncertainty associated with the vendor } \\
\text { decrease. }\end{array}$ & 0.083 & Not Supported \\
\hline $\begin{array}{l}\text { H3: In a service outsourcing situation, stronger vendor reputation negatively } \\
\text { influences buyers' a priori perceptions of vendor opportunism. }\end{array}$ & -0.701 & Supported \\
\hline $\begin{array}{l}\text { H4: In a service outsourcing situation, as vendor firm reputation increases, } \\
\text { buyers' a priori perceptions of technological uncertainty decrease. }\end{array}$ & -0.268 & Supported \\
\hline $\begin{array}{l}\text { H5: In a service outsourcing situation, there is a positive relationship between } \\
\text { buyers' a priori perceptions of technological uncertainty and opportunism } \\
\text { associated with a vendor. }\end{array}$ & 0.478 & Supported \\
\hline
\end{tabular}

Results for $\mathrm{H} 1$ which links vendor firm size negatively to buyer's perceptions of opportunism was significant in the opposite direction (beta $=0.446 ;$ p. <.05). H2 which links vendor firm size negatively to buyer's perceptions of technological uncertainty yielded a non-significant results (p. >.05). H3 which negatively links vendor firm reputation to buyer's perceptions of opportunism yielded a significant result and a beta of -0.701 (p. <.05) in support of $\mathrm{H} 3$.

$\mathrm{H} 4$ which examines vendor firm reputation as a negative influence on buyer's perceptions of technological uncertainty yielded a significant results and a beta of -0.268 (p. <.05) providing support for H4. Results for H5, which positively links buyer's perceptions of technological uncertainty to vendor opportunism, yielded significant results and a beta of 0.478 (p. <.05). Overall, results support $\mathrm{H} 3$, H4, and H5, but not H1 or H2. Squared multiple correlations for perceived opportunism was 0.55 and 0.15 for perceived technological uncertainty. Table 3 provides a summary of the hypotheses test results.

\section{DISCUSSION AND MANAGERIAL IMPLICATIONS}

This research shows that strong vendor reputation indeed serves as a key variable that reduces buyers' ex ante or a priori perceptions of vendor opportunism in a services' outsourcing context. This is consistent with findings of other scholars that research buyer-seller relationship in non-IT outsourcing contexts such as manufacturing (e.g., Hennart 1993; Houston \& Johnson, 2000). Doney and Cannon (1997) contend that positive vendor reputation instills trust among buyers thereby alleviating the need for costly postcontractual vendor management processes. From a managerial viewpoint, the importance of vendor reputation cannot be undermined when evaluating and selecting a vendor for an outsourced IT solution. Similarly, for vendors of such solutions, they must continue to focus on building a strong reputation for the brand itself as well as the products and services associated with it.

Outside of IT, the importance of vendor reputation cannot be undermined in other areas such as manufacturing and retail which involve an even greater reliance on effective supply chain ecosystems which often comprise multiple vendors thereby increasing the likelihood of vendor opportunism. deSouza and Haddud (2017) state that fully integrated supply chains require thorough integration across all operational aspects and processes. This further raises the importance of vendor reputation in terms of reliability and for being a team player in an integrated supply chain.

Vendor reputation was negatively related to buyer's perceptions of technological uncertainty, yielding several important implications. First, the support for $\mathrm{H} 4$ indicates that stronger overall reputation helps reduce buyers' perception of technological uncertainty, including the risk of obsolescence, associated with the vendor's solutions/offerings. Perception of technological uncertainty is likely to either keep buyers from purchasing from a vendor altogether or prompt them to seek only short-term transactions. Secondly, by remaining on the cutting-edge of IT, vendors are able to garner a reputation for product/service innovation. Within the software segment, for instance, Microsoft continues to develop upgrades for its operating system as well as other productivity applications and these updates and innovations are largely driven by the expectations of the customers as well as the innovationrelated reputation that the company has built for itself.

The significant support for the linkage between technological uncertainty and opportunism is in line with findings in extant literature that identify uncertainty (both technological and behavioral) as antecedents to opportunism (e.g., McNally \& Griffin, 2004; Mysen et al., 2010). From a managerial perspective, buyers must be aware that while they expect that IT providers be on the cutting-edge of technology, such technological changes can expose them to the risk of costly upgrades, technological obsolescence, and incompatibility. In certain cases, technological changes may even increase dependence on the vendor if the IT solutions being purchased are based on proprietary systems. From a vendor's perspective, given the presence of a linkage between technological uncertainty and buyer's perceptions of vendor opportunism, they must keep existing customers apprised of upcoming changes in their systems. Doing so is likely to build trust as opposed to using such product upgrades to squeeze new revenue from clients.

Despite the lack of support for $\mathrm{H} 1$, which negatively links vendor size to buyers' perception of opportunism, the findings offer rather valuable insights in that buyers of outsourced IT perceive a greater sense of opportunism from larger vendors than smaller firms offering such solutions. One potential explanation here, as suggested by Ganesan (1994) and Geyskens et al. (2006), is that buyers may perceive a greater sense of dependence on larger vendors 
thereby essentially creating barriers to exit the relationship. Vendor firm size also influences the degree of power one party in the exchange will have over another (Anderson \& Narus, 1990). In that regard, buyers may perceive a lack of power when purchasing outsourced IT solutions/services from national and global vendors. Regardless of the antecedents of dependence (such as supply constraints, channel member power, etc.), buyer-seller relationship research positively links dependence with opportunism (Heide, 1994).

From a managerial perspective, while larger vendors may have a better reputation as suggested by Doney and Cannon (1997), ex ante perceptions of opportunism on the part of the buyer may negatively impact their evaluation and selection by organizational IT buyers. Considering these findings, large vendors must engage in branding strategies that alleviate opportunism perceptions of B2B IT buyers. For instance, large vendors can focus on enhancing their sales and customer support functions in a way that conveys greater empathy for the customer - specifically small and mid-sized enterprise buyers. Moreover, large vendors must also improve their level of responsiveness to customer problems, specifically smaller buyers that may often feel neglected by a larger vendor. From an organizational buyer's perspective, these findings suggest that larger vendors are more likely to engage in ex post opportunism thereby essentially placing their own interests over those of the buyers. In that regard, when entering into a procurement relationship with larger vendors, buyers may have to closely monitor such relationships on an ongoing basis or build other contractual safeguards. Effective monitoring mechanisms while necessary under such conditions, however, are likely to increase the overall cost of doing business with larger vendors. This is even more likely to be the case for smaller buyers who may lack existing vendor monitoring or compliance systems in place.

For smaller vendors, the findings imply that these vendors must continue to differentiate themselves in the marketplace based on their ability to offer efficient and personalized solutions/service to their customers. Smaller vendors can also engage in positioning strategies that capitalize on the higher degree of perceived opportunism associated with large vendors as demonstrated by this study. For instance, while larger vendors are often perceived as less responsive to customer support needs of buyers, smaller vendors can position themselves as more efficient and effective in responding to complaints and other customer service issues.

\section{CONCLUSION, LIMITATIONS, AND FUTURE RESEARCH}

\subsection{Conclusion}

The study hypothesized five linkages and findings supported three of these linkages. A key finding of the study is that while vendor firm reputation negatively impacts buyers' perceptions of vendor opportunism, vendor firm size positively correlates with such perceptions. This is an important finding in that it creates a dilemma for vendors that otherwise may have a positive reputation, yet their larger size may signal higher degree of perceived opportunism to buyers of outsourced IT services - specifically mid-sized and smaller organizations.

The findings in this paper also offer an alternative perspective to what had been previously found in buyerseller and transaction cost research (e.g., Nooteboom, 1993; Doney \& Cannon, 1997; Larson et al., 2005) that labeled smaller suppliers/vendors as having lower reputation, greater short-term orientation, and lack of expertise, conditions that foster opportunism. This paper's findings portray larger vendor size as an antecedent to buyers' ex ante perceptions of opportunism. Also, the results of this study do not support the negative linkage between vendor size and buyers' perceptions of technological uncertainty. This bodes well for smaller vendors in that lack of perceived technological uncertainty based on vendor firm size is less likely to keep smaller IT outsourcing providers from effectively competing for business.

\subsection{Limitations}

This paper has some limitations. First, this study utilizes a cross-section of IT buyers across different industries and it is possible that IT buyers across different industries may vary in their perceptions of vendor opportunism and uncertainty. For instance, companies in high-tech industries such as telecom may not perceive a strong fear of technological obsolescence and may even engage in planned-obsolescence of their IT systems. However, compared to the telecom sector, healthcare providers may have more to lose in the wake of technological uncertainty.

Secondly, this study does not focus on a specific outsourced IT solution. It is likely that buyers of outsourced data center services or software-as-a service solution such as analytics may vary in their perception of vendor opportunism and technological uncertainty compared to those that purchase basic IT installation and maintenance services. Third, the lack of support for $\mathrm{H} 2$, that proposes a negative linkage between vendor size and technological uncertainty, essentially stems from a variety of industry-specific traits that include overall pace of technological change in outsourced IT solutions as well as increased understanding of advanced IT solutions on the part of organizational buyers. When asked which IT solution/function their organization outsourced in the past twelve months, the responses included solutions such as cloud computing, network security, network management, and application hosting. A majority, if not all, of these solutions have been available in the marketplace for quite some time now and it is likely that organizational buyers, specifically those with internal IT staff, may perceive limited technological uncertainty surrounding these solutions or their providers.

\subsection{Future Research}

Future research should include applying the present research model to specific industries in order to determine the similarities and differences across markets. Research can also add additional dependent variables to determine how vendor firm size and reputation influence buyers' perceptions of those variables. Some of those variables can include buyers' willingness-to-engage in a relationship or the need for vendor monitoring given higher perceptions of opportunism and technological uncertainty. 


\section{REFERENCES}

Anderson, J.C., and Narus, J.A. (1990). A model of distributor firm and manufacturer firm working partnerships. Journal of Marketing, 54(1), pp. 42-58.

Anderson, E., and Weitz, B. (1992). The use of pledges to build and sustain commitment in distribution channels. Journal of Marketing Research, 29(1), pp. 18-34.

Aubert, B.A., Patry, M., and Rivard, S. (1998). Assessing the risk of IT outsourcing. System Sciences, Proceedings of the Thirty-First Hawaii International Conference, 6, pp. 685692.

Bagozzi, R. P., Yi, Y., \& Phillips, L. W. (1991). Assessing construct validity in organizational research. Administrative Science Quarterly, 36(3), pp. 421-458.

Bahli, B., and Rivard, S. (2003). The information technology outsourcing risk: a transaction cost and agency theory-based perspective. Journal of Information Technology,18(3), pp. 211-221.

Basnet, C., and Seuring, S. (2016). Demand-oriented supply chain strategies - a review of the literature. Operations and Supply Chain Management, 9(2), pp. 73-89.

Bellin, H. (2015). Picking the right channel to reach your market. Journal of Marketing Channels, 22(3), pp. 231-234.

Brown, J. R., Krishen, A. S., \& Dev, C. S. (2014). The role of ownership in managing interfirm opportunism: a dyadic study. Journal of Marketing Channels, 21(1), pp. 31-42.

Cannon, J.P., and Perreault Jr., William D. (1999). Buyer-seller relationships in business markets. Journal of Marketing Research, 36(4), pp. 439-460.

Chen, I. J., Paulraj, A., and Lado, A. A. (2004). Strategic purchasing, supply management, and firm performance. Journal of Operations Management, 22(5), pp. 505-523.

Coase, R.H. (1937). The nature of the firm. Economica N.S,. 4(16), pp. 386-405.

Crosno, J.L., and Dahlstrom, R. (2008). A meta-analytic review of opportunism in exchange relationships. Journal of the Academy of Marketing Science, 36(2), pp. 191-201.

Dean, T.J., Brown, R.L., and Bamford, C.E. (1998). Differences in large and small firm responses to environmental context: strategic implications from a comparative analysis of business formations. Strategic Management Journal, 19(8), pp. 709-728.

deSouza, A., and Haddud, A. (2017). Supply chain management integration in maintenance and repair services sector. Operations and Supply Chain Management, 10(4), pp. 200213.

Digalwar, A. K., Borade, A., \& Metri, B. (2014). A fuzzy ahp approach for supplier selection. Operations and Supply Chain Management, 7(2), pp. 46-53.

Doney, P.M., and Cannon, J.P. (1997). An examination of the nature of trust in buyer-seller relationships. Journal of Marketing, 61(2), pp. 35-51.

Fombrun, C.J., Gardberg, N.A. \& Sever, J.M. (2000). The reputation quotient: A multi-stakeholder measure of corporate reputation. Journal of Brand Management, 7(4), pp. 241-255.

Fornell, C., \& Larcker, D. F. (1981). Evaluating structural equation models with unobservable variables and measurement error. Journal of Marketing Research, 18(1), pp. 39-50.

Ganesan, S. (1994). Determinants in long-term orientation in buyerseller relationships. Journal of Marketing, 58(2), pp. 1-19.

Geyskens, I., Steenkamp, J. E.M., and Kumar, N. (2006). Make, buy, or ally: a transaction cost theory meta-analysis. Academy of Management Journal, 49(3), pp. 519-543.

Gilley, K.M., and Rasheed, A. (2000). Making more by doing less: an analysis of outsourcing and its effects on performance management. Journal of Management. 26, pp. 763-790.

Hair, J. F., Black, W. C., Babin, B. J., and Anderson, R. E. (2010). Mutivariate Data Analysis (7th ed.). NJ: Prentice Hall.
Hawkins, T., Knipper, M.G., and Strutton, D. (2009). Opportunism in buyer-supplier relations: new insights from quantitative synthesis. Journal of Marketing Channels, 16(1), pp. 43-75.

Heide, J. B., and John, G. (1992). Do norms matter in marketing relationships? Journal of Marketing, 56(2), pp. 32-44.

Heide, J.B. (1994). Interorganizational governance in marketing channels. Journal of Marketing, 58(1), pp. 71-85.

Hennart, J. F. (1993). Explaining the swollen middle: Why most transactions are a mix of "market" and "hierarchy." Organization Science, 4(4), pp. 529-547.

Hill, C.W. L. (1990). Cooperation, opportunism, and the invisible hand: implications for transaction cost theory. The Academy of Management Review, 15(3), pp. 500-513.

Hoetker, Glenn. (2005). How much you know versus how well I know you: selecting a supplier for a technically innovative component. Strategic Management Journal, 26(1), pp. 75-96.

Houston, M.B., and Johnson, S.A. (2000). Buyer-supplier contracts versus joint ventures: determinants and consequences of transaction structure. Journal of Marketing Research, 37(1), pp. 1-15.

Hu, L. T., \& Bentler, P. M. (1999). Cutoff criteria for fit indexes in covariance structure analysis: Conventional criteria versus new alternatives. Structural Equation Modeling: A Multidisciplinary Journal, 6(1), pp. 1-55.

Hsu, C., Kannan, V.R., Leong, G.K., and Tan, K. (2006). Supplier selection construct: instrument development and validation. International Journal of Logistics Management, 17(2), pp. 213-239.

Jap, S.D., Robertson, D.C., Rindfleisch, A., and Hamilton, R. (2013). Low-stakes opportunism. Journal of Marketing Research, 50(2), pp. 216-227.

Krause, D.R., Ragatz, G.L., and Hughley, S. (1999). Supplier development from the minority supplier's perspective. Journal of Supply Chain Management, 35(4), pp. 33-41.

Kwon, I.G., and Suh, T. (2004). Factors affecting the level of trust and commitment in supply chain relationship. Journal of Supply Chain Management, 40(2), pp. 4-14.

Larson, P.D., Carr, P., and Dhariwal, K.S. (2005). SCM involving small versus large suppliers: relational exchange and electronic communication media. Journal of Supply Chain Management, 4l(1), pp. 18-29.

Lee, S. J., \& Kim, M. J. (2018). The Market Power, Environmental Uncertainty and Opportunistic Behavior Based on Transaction Cost Analysis Model in Networks. Journal of Marketing Thought, 5(2), pp. 34-43.

Macneil, I. (1980). Power, contract, and the economic model. Journal of Economic Issues, 14(4), pp. 909-923.

Manello, A., \& Calabrese, G. (2019). The influence of reputation on supplier selection: An empirical study of the European automotive industry. Journal of Purchasing and Supply Management, 25(1), pp. 69-77.

McNally, R.C., and Griffin, A. (2004). Firm and individual choice drivers in make-or-buy decisions: a diminishing role for transaction cost economics? Journal of Supply Chain Management, 40(1), pp. 4-17.

Morgan, J. P. (2000). New solutions to making EDI really work in purchasing. Purchasing, 129(6), pp. 42.

Mysen, T., Svensson, G., and Payan, J.M. (2011). The key role of opportunism in business relationships. Marketing Intelligence and Planning, 29(4), pp. 436-449.

Nooteboom, B. (1993). Firm size effects on transaction costs. Small Business Economics, 5(4), 283-295.

Ono, A., and Kubo, T. (2009). Manufacturer's intention to extend the relationships with distributors. Journal of Business and Industrial Marketing, 24(5-6), pp. 439-448.

Paswan, A. K. (2009). Environmental antecedents of channel opportunism. Journal of Marketing Channels, 16(4), pp. 309326.

Parasuraman, A., Zeithaml, V. A., and Berry, L. L. (1985). A conceptual model of service quality and its implications for 
future research. The Journal of Marketing, 49(4), pp. 41-50.

Pearson, J.N, and Ellram, L.M. (1995). Supplier selection and evaluation in small versus large electronics firms. Journal of Small Business Management, 33(4), pp. 53-65.

Petroni, A., and Braglia, M. (2000). Vendor selection using principal component analysis. Journal of Supply Chain Management, 36(2), pp. 63-69.

Podsakoff, P.M., MacKenzie, S.B., Lee, J, and Podsakoff, N.P. (2003). Common method biases in behavioral research: a critical review of the literature and recommended remedies. Journal of Applied Psychology, 88(5), pp. 879-903.

Pore, A. (2018). Transaction cost analysis, resource based view and mode of offshoring of services. Business Management Dynamics, 8(1), pp. 1-11.

Rindfleisch, A., and Heide, J.B. (1997). Transaction cost analysis: past, present, and future applications. Journal of Marketing, 61(4), pp. 30-54.

Ring, P.S., and Van de Ven, A. H. (1992). Structuring cooperative relationships between organizations. Strategic Management Journal, 13(7), pp. 483-498.

Rokkan, A. I., Heide, J.B., and Wathne, K.H. (2003). Specific investments in marketing relationships: expropriation and bonding effects. Journal of Marketing Research, 40(2), pp. 210-224.

Sarkis, J., and Talluri, S. (2002). A model for strategic supplier selection. Journal of Supply Chain Management, 38(1), pp.
$18-28$.

Stump, R.L., and Heide, J.B. (1996). Controlling supplier opportunism in industrial relationships. Journal of Marketing Research, 33(4), pp. 431-441.

Tumbat, G., \& Grayson, K. (2016). Authority Relinquishment in Agency Relationships. Journal of Marketing, 80(3), 42-59.

Walker, G., and Weber, D. (1984). A transaction cost approach to make-or-buy decisions. Administrative Science Quarterly, 29(3), pp. 373-391.

Wang, E.T. G. (2002). Transaction attributes and software outsourcing success: an empirical investigation of transaction cost theory. Information Systems Journal, 12(2), 153-181.

Wathne, K.H., and Heide, J.B. (2000). Opportunism in interfirm relationships: forms, outcomes, and solutions. Journal of Marketing, 64(4), pp. 36-51.

Weigelt, K., and Camerer, C. (2006). Reputation and corporate strategy: A review of recent theory and applications. Strategic Management Journal, 9(5), pp. 443-454.

Williamson, O. E. (1975). Markets and hierarchies: Analysis and antitrust implications. NY: The Free Pres.

Williamson, O.E. (1985). The economic institutions of capitalism. Simon and Schuster.

Williamson, O.E. (1996). The mechanisms of governance. Oxford University Press.

Dr. Imran M. Khan is an Assistant Professor of Practice at the University of Nebraska-Lincoln. He received his DBA in Marketing from Kennesaw State University (Kennesaw, Georgia). Dr. Khan has also served as faculty at Murray State University (Murray, Kentucky) and University of South Alabama (Mobile, Alabama). In addition, he has served as an analyst/consultant for some of the leading global market research and consulting organizations. In his role as an analyst/consultant, he focused on information and communications technology products, services, and solutions. He has also presented at several academic conferences and served as a reviewer for journals.

Dr. Brian N. Rutherford is the Executive Director of the Doctoral Program for the Coles College of Business at Kennesaw State University (Kennesaw, Georgia). He received his Ph.D. in Marketing from Georgia State University. Prior to joining the faculty at Kennesaw State University, he was a faculty member at Purdue University (West Lafayette, Indiana). Dr. Rutherford has served on over 30 dissertation committees and has published over 50 peer-reviewed journal articles. His research appears in leading publications that focus on sales management and business-to-business marketing. Dr. Rutherford serves as the Editor of Marketing Management Journal and one of the three Associate Editors of The Journal of Marketing Theory and Practice.

Dr. Alvin J. Williams is the Distinguished Professor of Marketing and Chair, Department of Marketing and Quantitative Methods, Mitchell College of Business, University of South Alabama. He is past President, Society for Marketing Advances and past Editor of the Journal of Supply Chain Management. Previous research has appeared in a number of journals, including, Industrial Marketing Management, Journal of Supply Chain Management, Journal of Business \& Industrial Marketing, Journal of Marketing Theory and Practice. He received a Ph.D. in Marketing from the University of Arkansas. 